\title{
Cholangioscopic management of proximally migrated biliary stent using a novel through-the-cholangioscope snare
}

Endoscopic biliary stenting using plastic or metal stents is an established therapy for the management of biliary obstruction due to benign or malignant disease. Stent migration (proximal or distal) has been reported to occur in $5 \%-10 \%$ of cases [1-3]. Distally migrated stents mostly pass through the intestine without incident, although bowel perforation, fistulas, and gastrointestinal bleeding have been reported. Proximally migrated stents can cause jaundice and cholangitis, and can be tricky to retrieve. Proximal migration is rare with pigtail stents [4]. This video describes the re-

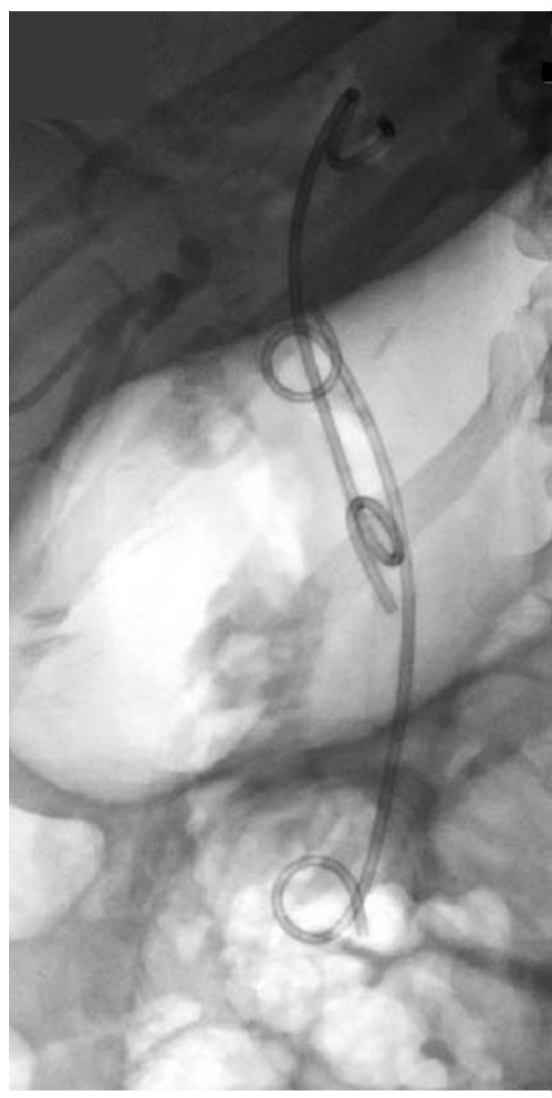

- Fig. 1 Migrated pigtail stent in the common bile duct, with the upper end within the left intrahepatic duct; the transpapillary stent is in the normal position. trieval of a proximally migrated pigtail stent using a novel through-the-cholangioscope snare ( $\downarrow$ Video 1 ).

A 37-year-old woman with choledocholithiasis underwent four conventional endoscopic retrograde cholangiopancreatographies (ERCPs), which were unsuccessful in clearing a large stone from the common bile duct (CBD). Two plastic pigtail stents were inserted and she was referred to our center for cholangioscopy using SpyGlass (Boston Scientific, Marlborough, Massachusetts, USA) and electrohydraulic lithotripsy (EHL).

The first ERCP at our center revealed that one of the pigtail stents had migrated proximally within the CBD ( $>$ Fig. 1). EHL successfully cleared the large stone. However, attempts to remove the migrated stent using techniques such as balloon placement parallel to the stent with traction retrieval ( $\triangleright$ Fig. 2 ) and SpyBite forceps (Boston Scientific) were unsuccessful.

At the second ERCP, the SpySnare (Boston Scientific) was introduced through the cholangioscope and manipulated to en- gage the lower end of the pigtail stent. As the stent was embedded within the left intrahepatic duct, significant traction was required to extract the stent; the stent was retrieved successfully.

This is the first case in the UK in which a SpySnare was used to retrieve a migrated stent. Various conventional techniques include balloon placement parallel to the stent with traction retrieval, fluoroscopyguided use of biopsy forceps, use of a Soehendra stent retriever and wire-guided basket, etc. The newer techniques include using a cholangioscope with various through-the-cholangioscope devices such as SpyBite forceps and SpySnare.

Endoscopy_UCTN_Code_CPL_1AK_2AD

\section{Competing interests}

Dr. Webster has received honoraria, support for educational meetings, and advisory board fees from Boston Scientific Inc.

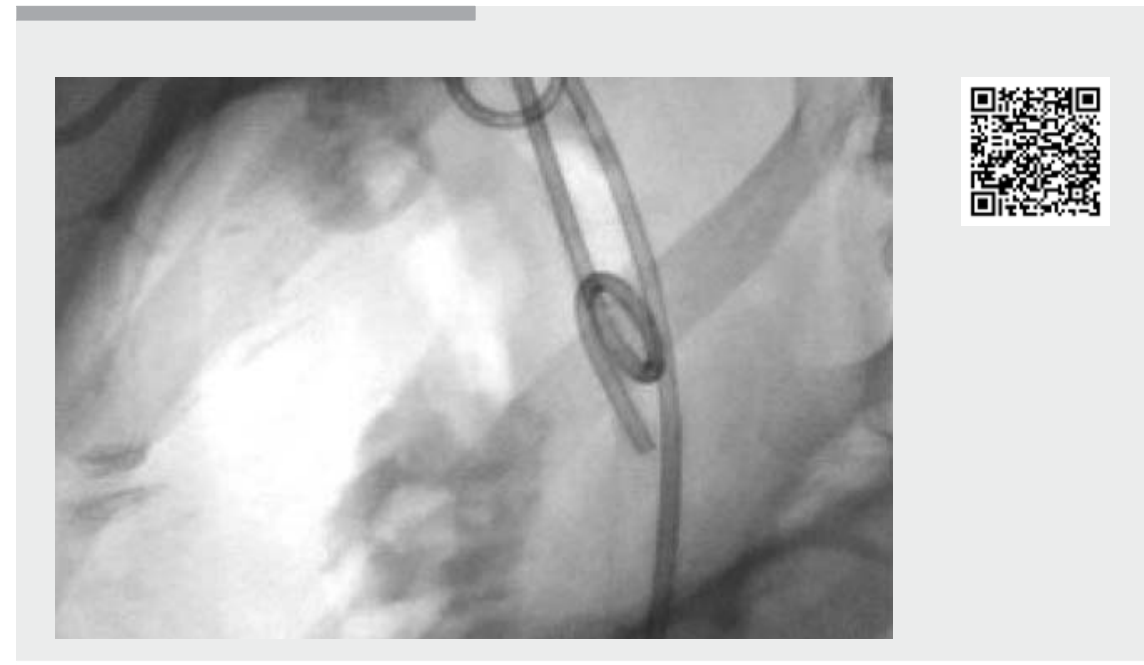

Video 1 Cholangioscopy-assisted retrieval of a proximally migrated common bile duct stent using a SpySnare (Boston Scientific, Marlborough, Massachusetts, USA). 


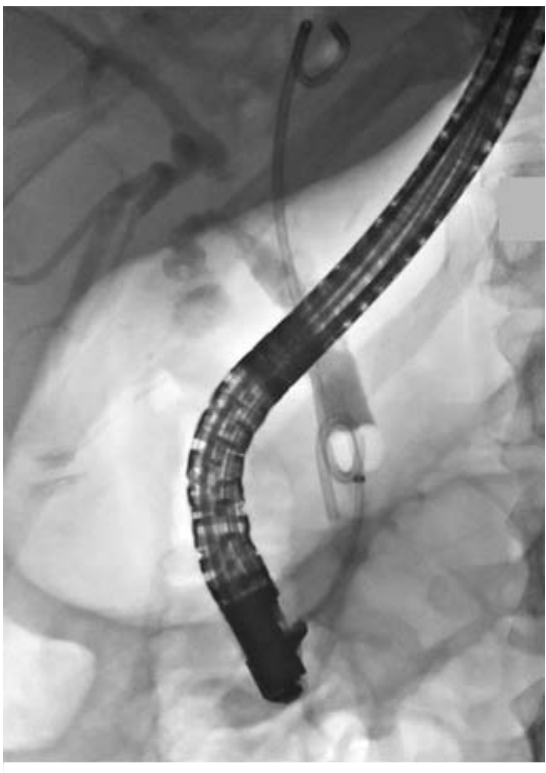

Fig. 2 Balloon placement parallel to the stent with traction retrieval.
The authors

\section{Sreelakshmi Kotha', Philip Berry', George}

Webster ${ }^{2}$, Terry Wong'

1 Department of Gastroenterology, Guy's and St Thomas' Hospital, London, United Kingdom

2 Department of Pancreaticobiliary Medicine, University College London, London, United Kingdom

Corresponding author

\section{Sreelakshmi Kotha, MD}

Department of Gastroenterology, Guy's and St Thomas' Hospital, Westminster Bridge Rd, London SE1 7EH, United Kingdom Fax: +44-20-71887188

sreelakshmi_kotha@yahoo.com

\section{References}

[1] Namdar T, Raffel AM, Topp SA et al. Complications and treatment of migrated biliary endoprostheses: a review of the literature. World J Gastroenterol 2007; 13: 5397 - 5399

[2] Akbulut S, Cakabay B, Ozmen CA et al. An unusual cause of ileal perforation: report of a case and literature review. World J Gastroenterol 2009; 15: 2672-2674
[3] Johanson J, Schmalz M, Geenen J. Incidence and risk factors for biliary and pancreatic stent migration. Gastrointest Endosc 1992; 38: $341-346$

[4] Barton RJ. Migrated double pigtail biliary stent causes small bowel obstruction. ] Gastroenterol Hepatol 2006; 21: $783-784$

\section{Bibliography}

DOI https://doi.org/10.1055/a-0977-2488

Published online: 9.8.2019

Endoscopy 2020; 52: E5-E6

(c) Georg Thieme Verlag KG

Stuttgart · New York

ISSN 0013-726X

\section{ENDOSCOPY E-VIDEOS \\ https://eref.thieme.de/e-videos}

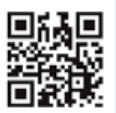

Endoscopy E-Videos is a free access online section, reporting on interesting cases and new

techniques in gastroenterological endoscopy. All papers include a high quality video and all contributions are freely accessible online.

This section has its own submission website at

https://mc.manuscriptcentral.com/e-videos 